\title{
Comparison of demineralized bone matrix and hydroxyapatite as carriers of Escherichia coli recombinant human BMP-2
}

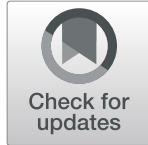

Yuan-Zhe Jin ${ }^{1,2}$, Guang-Bin Zheng ${ }^{3}$, Jae Hyup Lee ${ }^{1,4,5^{*}}$ (D) and Shi-Huan Han ${ }^{1,6}$

\begin{abstract}
Background: Autograft has been widely used in various orthopedic and dental surgery for its superior osteogenicity, osteoinductivity and osteoconductivity. But the available volume of the autograft is limited and the efficacy of it is highly affected by the condition of the patients. Therefore, growth factors such as Escherichia coli bone morphogenetic protein-2 (ErhBMP-2) has been widely used in some countries and regions with various carriers that could affect the effects of the growth factors. Demineralized bone matrix (DBM) has been widely used as a bone graft substitute and growth factor carrier, but its effect as a carrier of ErhBMP-2 was less investigated.

Materials and methods: Rat calvaria defect model was used in this study. We implanted ErhBMP-2 with DBM or hydroxyapatite (HA) as a carrier in $8 \mathrm{~mm}$ calvaria defect and compared their bone regeneration effect in 4th week and 8th week after implantation with micro-CT and histology. The data was analyzed with one-way ANOVA method with Bonferroni post-hoc analysis.
\end{abstract}

Result: The group with DBM as the carrier showed significantly higher bone volume and bone thickness than the groups with HA as the carrier in both weeks. And the histology sections showed less adipose tissue formed in the groups with DBM as the carrier.

Conclusion: DBM could be a better carrier for ErhBMP-2 than HA.

Keywords: Bone morphogenetic protein-2, Demineralized bone matrix, Hydroxyapatite, Carrier, Bone regeneration

\section{Background}

Autologous bone graft has been widely used in trauma, spine, and dental surgery to promote bone regeneration [1]. But in the cases of large bone defects, multiple bone harvesting history or metabolic bone diseases, the autologous bone graft could be inadequate for use [2]. Therefore, bone substitutes with growth factors, such as demineralized bone matrix (DBM) with Escherichia coli recombinant human bone morphogenetic protein-2

\footnotetext{
* Correspondence: spinelee@snu.ac.kr

'Department of Orthopedic Surgery, College of Medicine, Seoul National University, Seoul 03080, South Korea

${ }^{4}$ Department of Orthopedic Surgery, SMG-SNU Boramae Medical Center, 39 Boramae Gil, Dongjak-Gu, Seoul 156-707, South Korea

Full list of author information is available at the end of the article
}

(ErhBMP-2) have been widely used for promoting bone regeneration [3-7]. The ErhBMP-2 has been proved to have comparable osteoinductivity with the mammalian cell derived BMP-2 at both pre-clinical and clinical level, which also had advantage of easy accessing and lower cost $[8,9]$. The carriers immobilize the growth factor at the particular site for a sufficient period for inducing bone formation and affects the therapeutic effect of BMP-2 [7]. Hydroxyapatite (HA) is an osteoconductive calcium phosphate ceramic that has a similar chemical structure with inorganic component of bone and have been proved to be a carrier for ErhBMP-2 $[8,10-13]$. However, it had low fracture toughness and degradability, and the remnant HA impedes bone remodeling that made it a less optimal carrier [1, 14]. Demineralized

(c) The Author(s). 2021 Open Access This article is licensed under a Creative Commons Attribution 4.0 International License, which permits use, sharing, adaptation, distribution and reproduction in any medium or format, as long as you give appropriate credit to the original author(s) and the source, provide a link to the Creative Commons licence, and indicate if changes were made. The images or other third party material in this article are included in the article's Creative Commons licence, unless indicated otherwise in a credit line to the material. If material is not included in the article's Creative Commons licence and your intended use is not permitted by statutory regulation or exceeds the permitted use, you will need to obtain permission directly from the copyright holder. To view a copy of this licence, visit http://creativecommons.org/licenses/by/4.0/ The Creative Commons Public Domain Dedication waiver (http://creativecommons.org/publicdomain/zero/1.0/) applies to the data made available in this article, unless otherwise stated in a credit line to the data. 
bone matrix (DBM) is another BMP-2 carrier, which is both osteoinductive and degradable $[15,16]$. It has been practiced over several years for its safety and excellent biocompatibility as both scaffold for bone regeneration and carrier for growth factors [17-19]. But as far as we know, no direct comparison was conducted between the effect of HA and DBM as the carrier of ErhBMP-2. Therefore, we loaded ErhBMP-2 on HA and DBM and compared their effect on bone regeneration with rat calvaria defect model.

\section{Method}

\section{Rat calvarial defect model}

The procedures that involved the use of animals for the rat calvarial defect experiment were approved by the international animal care and use committee (SNUH IACUC No.13-0348). For animal welfare and reduction of animal number, a group of data from a previously published article with the same setting as in this study was used [20]. Eight-week-old male Sprague-Dawley rats (200-220 g, total $N=130$ ) were used for the animal experiment, all animals were kept in a 12:12 dark/light cycle, specific-pathogen-free cage and were provided with abundant food and water. The experiments were performed after 1 week of stabilization period. The HA granules with $0.6 \mathrm{~mm}$ to $1 \mathrm{~mm}$ size were soaked into the $0.15 \mathrm{ml}$ saline containing different dosage of BMP for 5 min. In the groups with DBM as carrier, the BMP was injected into the syringe containing DBM. After the carriers were soaked with BMP-2, the carriers were gently deposited inside the defect. The animals were randomly assigned to following 5 groups: HA (Novosis, CGBio, Korea) $25 \mathrm{mg}$; DBM $0.05 \mathrm{ml}$; ErhBMP-2 $25 \mu \mathrm{g}$ (Novosis, CGBio, Korea) + HA 25 mg (Novosis, CGBio, Korea); ErhBMP-2 $2.5 \mu \mathrm{g}$ (Novosis, CGBio, Korea) + HA $25 \mathrm{mg}$ (Novosis, CGBio, Korea); ErhBMP-2 $2.5 \mu \mathrm{g}$ (Novosis, CGBio, Korea) + DBM $0.05 \mathrm{ml}$ (Rafugen DBM gel, Cellmud, Korea). The animals were euthanized in their 4th and 8th weeks after surgery, and each group had 13 animals at each time point.

Animals were anesthetized with intraperitoneal injections of $20 \mathrm{mg} / \mathrm{kg}$ Zoletil and $10 \mathrm{mg} / \mathrm{kg}$ xylazine. After an $8 \mathrm{~mm}$ calvarial defect was made with a high speed trephine burr. The BMP-2 containing carrier was implanted in the defect and the defect was sutured layer by layer [21].

All animals were sacrificed with a $\mathrm{CO}_{2}$ chamber under deep anesthesia at their 4th or 8th week after experiments. The calvaria were harvested and fixed in $10 \%$ formalin for micro-CT evaluation and histological assessments.

\section{Micro-CT}

The samples were scanned with a Skyscan 1172 microCT scanner (Bruker, Belgium) with the following format: pixel size of $11.93 \mu \mathrm{m}$, Al filter of $0.5 \mathrm{~mm}$, energy of 70
$\mathrm{kV}$, current of $141 \mu \mathrm{A}$, rotation step of $0.4^{\circ}$. The raw images were reconstructed using the NRecon package (Bruker, Belgium) and analyzed with the CT Analyzer software (CT-An, Bruker, Belgium). The threshold values in grayscale of the newly-formed bone were referred to the values of native bone and was set as 110 to 240. Bone morphometric parameters of newly formed bone inside the defect, including percent bone volume (BV/TV), bone surface/volume ratio (BS/BV), trabecular bone pattern factor (Tb.Pf), structure model index (SMI), trabecular bone thickness (Tb.Th), trabecular number (Tb.N), trabecular separation (Tb.Sp), and degree of anisotropy (DA) were analyzed. The data used in the DBM/ErhBMP-2(2.5 $\mu \mathrm{g})$ group was previously used in another published article [9].

\section{Histology}

The samples were fixed in 10\% formalin and sequentially dehydrated in 80 to $100 \%$ ethyl alcohol, infiltrated, and embedded in Technovit 7200 resin (EXAKT, Germany). The resin was solidified with a polymerization system (EXAKT, Germany), the hardened resin blocks were sectioned by using a cutting system (EXAKT, Germany) to $200 \mu \mathrm{m}$ thick slices, and the slices were ground to a thickness of $50 \mu \mathrm{m}$ by using a grinding system (EXAKT, Germany). The ground slices were stained with hematoxylin and eosin and the stained bone formations in the scaffolds were observed with an optical microscope.

\section{Statistic}

In the micro-CT analysis, the two rhBMP-2 groups were compared with one-way ANOVA method and followed by Bonferroni post-hoc analysis with SPSS 20 (IBM Corp, Armonk, NY: IBM Corp). $P$ value less than 0.05 was deemed as statistically significant. The data were presented as mean and standard deviation.

\section{Result \\ Micro-CT \\ Effect of $H A$ and DBM as bone substitute}

In the 4th week, DBM group had significantly higher $\mathrm{BV} / \mathrm{TV}, \mathrm{Tb}$. Th, and $\mathrm{Tb} . \mathrm{N}$, and significantly lower BS/ $\mathrm{BV}, \mathrm{Tb}, \mathrm{Pf}$ and SMI than the HA group. The parameters indicated the new bone in the DBM group had more volume, number, thicker structure, more continuity, more sphere void, and less complex surface than the new bone in the HA group (Fig. 1a).

In the 8th week, the DBM group had similar BV/TV with HA, but significantly higher $\mathrm{Tb}$. Sp and $\mathrm{Tb}$. Th, and significantly lower Tb. Pf and SMI. The parameters indicated the new bone in the DBM group still had more continuity and sphere void, but the percent bone volume became similar to that of HA group. Moreover, the separation between the newly formed bone in the DBM 

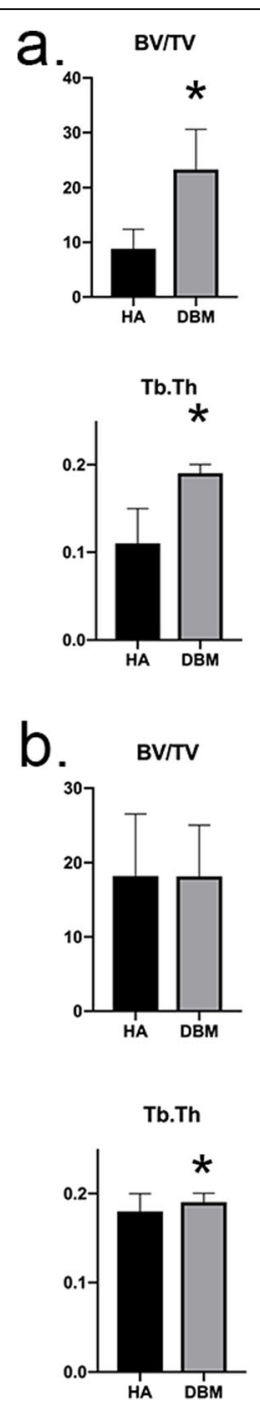
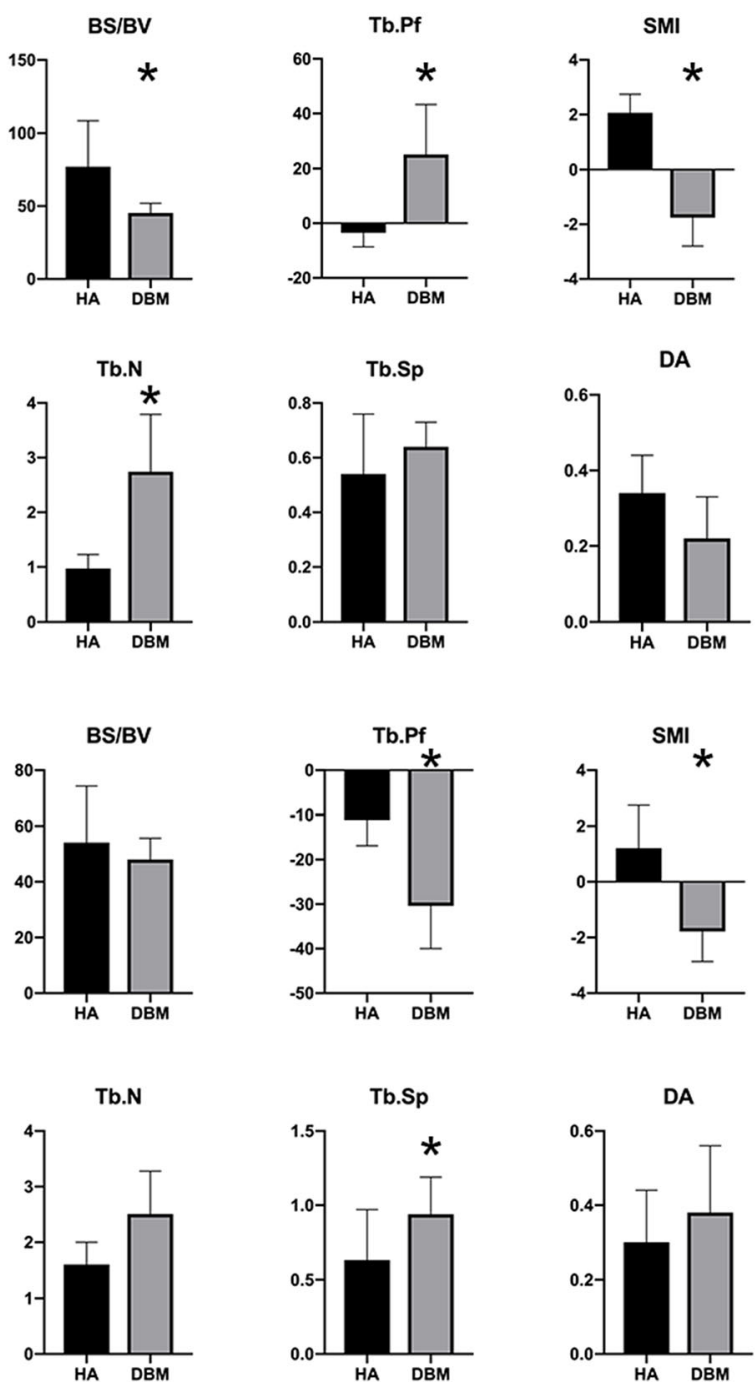

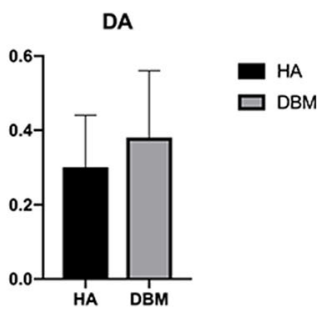

Fig. 1 micro-CT results of the HA and DBM groups. a Micro-CT results in the 4th week. DBM group had significantly higher BV/TV, Tb. Th, and Tb. $\mathrm{N}$, and significantly lower BS/BV, Tb,Pf and SMl than the HA group. b Micro-CT results in the 8th week. The DBM group had similar BV/TV with HA, but significantly higher Tb. Sp and Tb. Th, and significantly lower Tb. Pf and SMI. *, $p$ value is less than 0.05

group became significantly wider than that in HA group (Fig. 1b).

\section{Effect of $H A$ and DBM as carriers of BMP-2}

In the 4th week, DBM/ErhBMP-2 $(2.5 \mu \mathrm{g})$ group had 52 and $30 \%$ higher BV/TV than HA/ErhBMP-2 $(2.5 \mu \mathrm{g})$ group and HA/ErhBMP-2 $(25 \mu \mathrm{g})$ group, with statistical significance (Fig. 2a) Also, DBM/ErhBMP-2 $(2.5 \mu \mathrm{g})$ group had significantly higher $\mathrm{Tb}$. Th than the HA/ ErhBMP-2 $(2.5 \mu \mathrm{g})$ group and HA/ErhBMP-2 $(25 \mu \mathrm{g})$ group without significant difference in $\mathrm{Tb}$. $\mathrm{N}$ or Tb.Sp. The significantly lower SMI in DBM/ErhBMP-2(2.5 $\mu \mathrm{g})$ group indicated a more spherical structured bone formed in the DBM/ErhBMP-2 $(2.5 \mu \mathrm{g})$ group.

In the 8th week, the BV/TV of DBM/ErhBMP$2(2.5 \mu \mathrm{g})$ group was 52 and $65 \%$ higher than that of HA/
ErhBMP-2 $(2.5 \mu \mathrm{g})$ group and HA/ErhBMP-2(25 $\mu \mathrm{g})$ group, with statistical significance. Consistent with the result in the 4th week, the DBM/ErhBMP-2 $(2.5 \mu \mathrm{g})$ group had significantly higher $\mathrm{Tb}$. Th than the HA/ ErhBMP-2 $(2.5 \mu \mathrm{g})$ group and HA/ErhBMP-2 $(25 \mu \mathrm{g})$ group. The significantly lower SMI in DBM/ErhBMP$2(2.5 \mu \mathrm{g})$ group indicated more spherical structured bone formed in the DBM/ErhBMP-2(2.5 $\mu \mathrm{g})$ (Fig. 2b).

The parameters indicated the bone formed DBM/ ErhBMP-2 $(2.5 \mu \mathrm{g})$ group maintained its advantage in bone volume, and the bone had more sphere void and more continuity structure. Additionally, the Tb. Th was slightly but significantly higher in DBMErhBMP$2(2.5 \mu \mathrm{g})$ group in the 4 th week, while in the 8 th week, the $\mathrm{Tb}$. Th of DBM/ErhBMP-2(2.5 $\mu \mathrm{g})$ group became $28 \%$ higher than that of the other two groups. The 

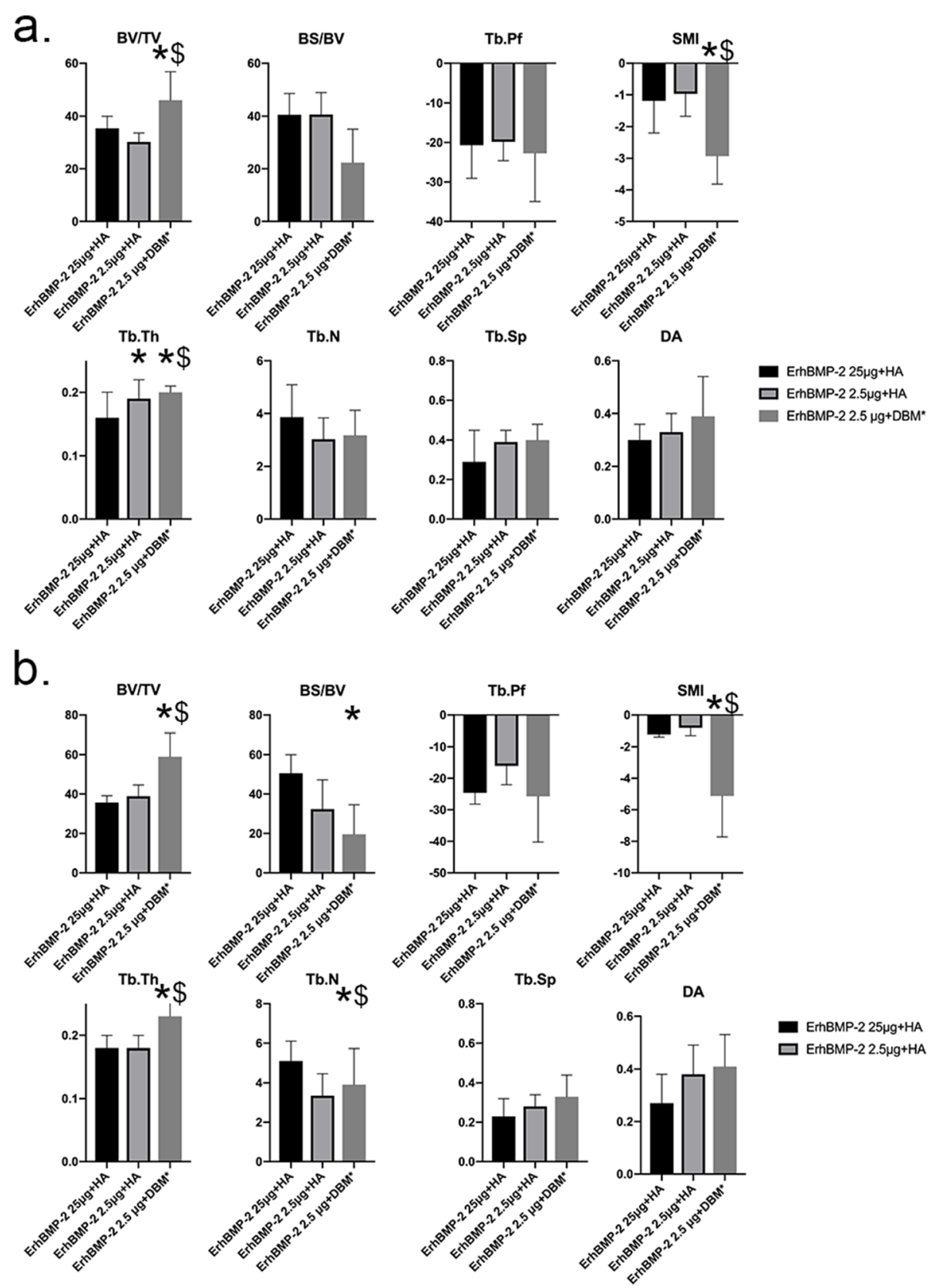

Fig. 2 micro-CT results of groups with BMP-2. a Micro-CT results in the 4th week. DBM/ErhBMP-2(2.5 $\mu \mathrm{g})$ group had significantly higher BV/TV and Tb. Th than HA/ErhBMP-2 $(2.5 \mu \mathrm{g})$ group and HA/ErhBMP-2 $(25 \mu \mathrm{g})$ group. Also, the DBM/ErhBMP-2 $(2.5 \mu \mathrm{g})$ group had significantly lower SMl than the other two groups. $\mathbf{b}$ Micro-CT results in the 8th week. The DBM/ErhBMP-2 $2.5 \mu \mathrm{g})$ group had significantly higher BV/TV and Tb. Th and significantly lower SMl than the other two groups. ${ }^{*}, p$ value is less than 0.05 , compare with HA/ErhBMP-2(25 $\left.\mu \mathrm{g}\right)$ group. ${ }^{\$}, p$ value is less than 0.05 , compare with HA/ErhBMP-2 $(2.5 \mu \mathrm{g})$ group

results consistently showed the DBM/ErhBMP-2(2.5 $\mu \mathrm{g})$ group achieved the best bone regeneration at both time points (Fig. 3).

\section{Histology}

The histology sections showed consistent with micro-CT result. In the 4th week, the DBM group showed more bone than HA. The HA/ErhBMP-2 $(25 \mu \mathrm{g})$ group had slightly more bone than HA/ErhBMP-2(2.5 $\mu \mathrm{g})$ group. The DBM/ErhBMP-2 $(2.5 \mu \mathrm{g})$ group had the most bone formed. Additionally, the bone in DBM/ErhBMP$2(2.5 \mu \mathrm{g})$ group showed denser construct and less fatty tissue formed inside the newly generated bone than the other groups (Fig. 3).

In the 8th week, HA and DBM showed similar bone regeneration. HA/ErhBMp-2 $(25 \mu \mathrm{g})$ group showed similar 


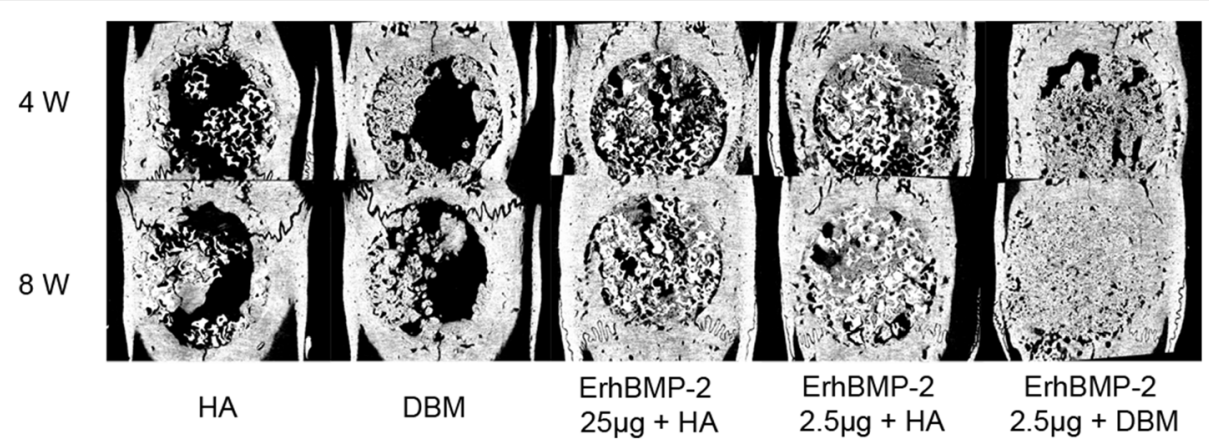

Fig. 3 micro-CT images. ErhBMP-2 $2.5 \mu \mathrm{g}+$ DBM had the best bone regeneration in 4th and 8th week. No significant difference was observed between ErhBMP-2 $2.5 \mu \mathrm{g}+\mathrm{HA}$ and ErhBMP-2 $25 \mu \mathrm{g}+\mathrm{HA}$ at both time points. DBM group achieved faster bone regeneration than HA in the 4th week, but had similar bone formed with HA group in the 8th week. The data in DBM + ErhBMP-2 group was reported in a previous article [20]

bone volume and more sphere-shaped void with HA/ ErhBMP-2 $(2.5 \mu \mathrm{g})$ group. The DBM/ErhBMP-2(2.5 $\mu \mathrm{g})$ group had the most bone generated in the defect, and the bone was the thickest among the groups. Also, the DBM/ ErhBMP-2 $(2.5 \mu \mathrm{g})$ group had the least fatty tissue in the newly formed bone (Fig. 4).

\section{Discussion}

Critical bone defect that cannot heal spontaneously requires bone grafting to provide sufficient endogenous regeneration. The standard grafting material is still the autologous bone, despite its complications. Following the development in the tissue engineering, the ErhBMP-
2 has been used in the clinic for promoting bone regeneration $[8,22]$. Despite the inspired outcomes in preclinical studies, the effectiveness of BMP-2 in clinical cases still need to be furtherly proved, such as nonunion. One possible reason is the fast release from the used carrier that mostly determines the effect of the BMP-2, therefore, choosing an appropriate carrier for the ErhBMP-2 remains to be an active area of research. $\mathrm{DBM}$ is an attractive bone substitute that can release the BMP-2 with a pattern of a 4-day burst release followed with a 14-day continuous release [16, 23].

The effect of DBM as the carrier was compared in vivo with $\mathrm{HA}$, another widely used bone substitute

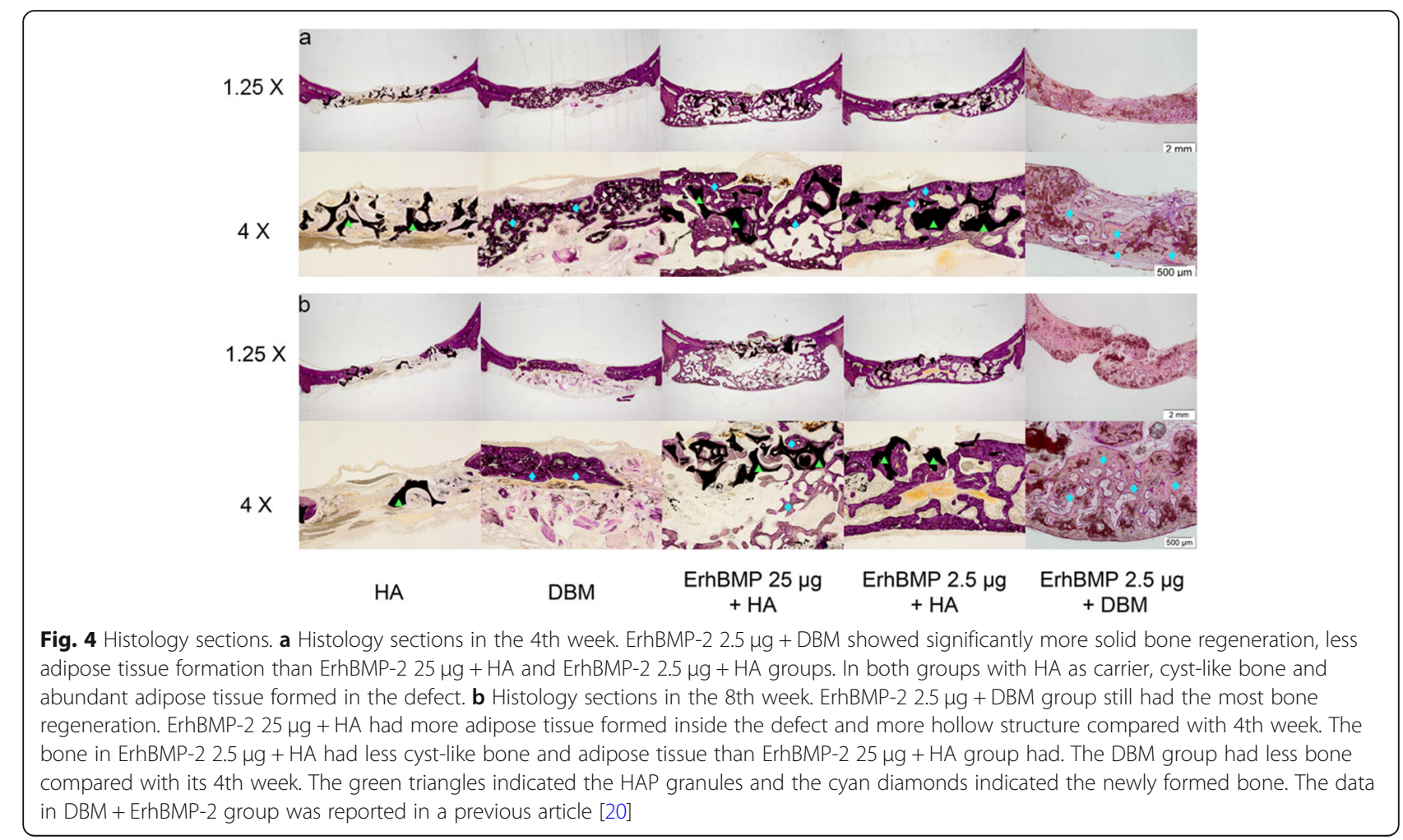


with a rapid BMP-2 releasing pattern [24]. In the comparison of mere DBM and HA, the micro-CT showed similar bone regeneration on the 8th week. But with BMP-2 added, the DBM showed significantly and obviously more bone regeneration at both time points compared with its same dosage counterpart. The possible reasons might be the growth factors that already contained in the DBM that ErhBMP-2 synergistically elevated bone regeneration with ErhBMP-2 and its superior transfer rate and releasing pattern of BMP-2 [19]. More surprisingly, we noticed even adding 10 times dosages of BMP-2 in HA did not significantly increased bone regeneration at both time points, which furtherly proved merely increasing the dosage of ErhBMP-2 cannot guarantee a better bone regeneration.

In previous studies, it has been attempted to optimize the release of rhBMP-2 from carrier to achieve better bone regeneration. Zhu et al. investigated a collagenbinding rhBMP-2, and this structure modified rhBMP-2 achieved significantly slower release and better bone formation than the commercial BMP-2 while both with $\mathrm{DBM}$ as a carrier [17]. Also, a heparin conjugated carrier system was proved to reduce adipose tissue formation and enhance bone generation by ErhBMP-2 [25, 26]. However, the new product listed above remained in preclinical experiment phases and needed further investigation of their safety and effect character. Compare with the newly fabricated material and modified rhBMP-2, the HA, DBM, and rhBMP-2 used in this study were all commercially available. Therefore, the result from this study might offer more practical evidence for using ErhBMP-2 in a clinical situation and provide a possible combination of ErhBMP-2 and its carrier system.

On the other side, though DBM/ErhBMP-2 $(2.5 \mu \mathrm{g})$ performed the best bone regeneration, DBM itself might not be an ideal carrier. Firstly, all DBM clinical product is from a human donor. Though donor qualification process is rigorous and stringent, using DBM still has a risk of disease transmission [15]. Moreover, the efficiency could also be affected by donor variability, like age and gender [27]. Secondly, the product of DBM was in powder shape and it requires other carriers for handling, and the carriers used to mix DBM could bring variety in the final efficacy [27].

In selecting the bone defect model, we used a rat calvaria defect model, which has been widely used for generating standardized defects [28]. But it cannot simulate all bone defect diseases in a clinical situation. Because the calvaria was composed of flat bone and healed through intramembranous ossification, and it cannot be used to assess the material under physiological mechanical loads $[28,29]$. The micro-CT analysis might overestimate the bone formation in groups with HA due to the difficulties in separating HA from newly formed bone. But even considering the possible overestimated bone volume in HA group, the groups with DBM as the carrier showed higher bone volume. Therefore, with the consistent trend observed from histology sections, we believe the result from micro-CT could be considered reliable. In current stage of study, the release kinetics, transfer rate or the degradation characteristics of the two carriers were not investigated, which brought difficulties in furtherly interpreting the reasons of the superior effect of the DBM to HA. In further studies, the reasons of the better performance of DBM should be elucidated. At current stage of study, the surface morphology of the DBM or HA was not obtained, which brought hassles in analyzing the possible reasons of the result and was a limitation of this study. Additionally, the histomorphometry analysis result should be performed to bring more concise results. The performance of DBM as a carrier of ErhBMP-2 should be evaluated with defect models that can simulate spinal fusion and long bone defect, in which bone regenerates through endochondral ossification, blood flow might dilute the dosage of ErhBMP-2 and mechanical stress could be load $[28,29]$.

\section{Conclusion}

DBM presented a potent carrier of ErhBMP-2 the induced significantly better bone regeneration than HA. The combination of DBM and ErhBMP-2 that could be a feasible bone substitute for augmentation of bone defect.

\section{Abbreviations}

BV/TV: Percent bone volume; BS/BV: Bone surface/volume ratio; DA: Degree of anisotropy; DBM: Demineralized bone matrix; ErhBMP-2: Escherichia recombinant human bone morphogenetic protein-2; HA: Hydroxyapatite; SMI: Structure model index; Tb.Pf: Trabecular bone pattern factor;

Tb.Th: Trabecular bone thickness; Tb.N: Trabecular number; Tb.Sp: Trabecular separation

\section{Authors' contributions}

JIN YZ contributed to acquisition, analysis, and interpretation of data, drafted and revised the manuscript. ZHENG GB contributed to performing the experiments. LEE JH contributed to conception and design of the work, interpretation of the data and revising the manuscript. HAN SH contributed to analysis and interpretation of the data and revising the manuscript. All the authors approved the submitted version.

\section{Funding}

This study was supported by a research grant for animal studies from Daewoong Pharmaceutical (Seoul, Korea) (No. 800-20140080).

\section{Availability of data and materials}

The data that support the findings of this study are available from the corresponding author, JHL, upon reasonable request.

\section{Declarations}

Ethics approval and consent to participate

The procedures that involved the use of animals for the rat calvarial defect experiment were approved by the international animal care and use committee (SNUH IACUC No.13-0348). 


\section{Consent for publication}

Not applicable.

\section{Competing interests}

The authors declare that they have no competing interests.

\section{Author details}

'Department of Orthopedic Surgery, College of Medicine, Seoul National University, Seoul 03080, South Korea. ${ }^{2}$ The First Hospital of Jilin University, Changchun City 130021, China. ${ }^{3}$ Department of Orthopaedics, Taizhou Hospial of Zhejiang Province, Linhai 317000, Zhejiang, China. ${ }^{4}$ Department of Orthopedic Surgery, SMG-SNU Boramae Medical Center, 39 Boramae Gil, Dongjak-Gu, Seoul 156-707, South Korea. ${ }^{5}$ Department of Orthopaedic Surgery, Seoul National University, College of Medicine, Institute of Medical and Biological Engineering, Seoul National University Medical Research Centre, SMG-SNU Boramae Medical Centre, Boramae-ro 5-gil 20, Dongjak-gu, Seoul 07061, South Korea. ${ }^{6}$ Department of Orthopedic Surgery, YanBian University Hospital, Yanji 133000, Jilin Province, China.

Received: 17 May 2021 Accepted: 15 July 2021

Published online: 03 August 2021

\section{References}

1. Sohn HS, Oh JK. Review of bone graft and bone substitutes with an emphasis on fracture surgeries. Biomater Res. 2019;23(1):9. https://doi.org/1 0.1186/s40824-019-0157-y.

2. Spivak JM, Hasharoni A. Use of hydroxyapatite in spine surgery. Eur Spine J. 2001;10 Suppl 2(0940-6719 (Print)):S197-204.

3. Jin $\mathrm{YZ}$, Lee $\mathrm{JH}$. Mesenchymal stem cell therapy for bone regeneration. Clin Orthop Surg. 2018;10(3):271-8. https://doi.org/10.4055/cios.2018.10.3.271.

4. Yun $Y-R$, Jang JH, Jeon E, Kang W, Lee $S$, Won J-E, et al. Administration of growth factors for bone regeneration. Regen Med. 2012;7(3):369-85. https:// doi.org/10.2217/rme.12.1.

5. Russow G, Jahn D, Appelt J, Mardian S, Tsitsilonis S, Keller J. Anabolic therapies in osteoporosis and bone regeneration. Int J Mol Sci. 2018;20(1):83.

6. Liu G, Tan JH, Yang C, Ruiz J, Wong HK. A computed tomography analysis of the success of spinal fusion using ultra-low dose ( $0.7 \mathrm{mg}$ per facet) of recombinant human bone morphogenetic protein 2 in multilevel adult degenerative spinal deformity surgery. Asian Spine J. 2018;12(6):1010-6. https://doi.org/10.31616/asj.2018.12.6.1010.

7. Vishal A, Mukty S. A review on carrier systems for bone morphogenetic protein-2. J Biomed Mater Res B Appl Biomater. 2017;105(4):904-25.

8. Cho JH, Lee JH, Yeom JS, Chang BS, Yang JJ, Koo KH, et al. Efficacy of Escherichia coli-derived recombinant human bone morphogenetic protein2 in posterolateral lumbar fusion: an open, active-controlled, randomized, multicenter trial. Spine J. 2017;17(12):1866-74. https://doi.org/10.1016/j. spinee.2017.06.023.

9. Jin YZ, Zheng GB. Escherichia coli BMP-2 showed comparable osteoinductivity with Chinese hamster ovary derived BMP-2 with demineralized bone matrix as carrier; 2019. p. 1-10.

10. You H, Yoon SR, Lim HC, Lee JS, Jung UW, Choi SH. Bone regenerative efficacy of limited-dose Escherichia coli-derived rhBMP-2 with biphasic calcium phosphate carrier in rabbit calvarial defect model. Implant Dent. 2016;25(1):16-23. https://doi.org/10.1097/ID.0000000000000364.

11. Chung $\mathrm{CH}$, Kim YK, Lee JS, Jung UW, Pang EK, Choi SH. Rapid bone regeneration by Escherichia coli-derived recombinant human bone morphogenetic protein-2 loaded on a hydroxyapatite carrier in the rabbit calvarial defect model. Biomater Res. 2015;19(1):17. https://doi.org/10.1186/ s40824-015-0039-x.

12. Lee JH, Ryu MY, Baek HR, Lee KM, Seo JH, Lee HK, et al. Effects of porous beta-tricalcium phosphate-based ceramics used as an E. coli-derived rhBMP2 carrier for bone regeneration. J Mater Sci Mater Med. 2013;24(9):2117-27. https://doi.org/10.1007/s10856-013-4967-5

13. Lee $J H, Y u$ CH, Yang JJ, Baek HR, Lee KM, Koo TY, et al. Comparative study of fusion rate induced by different dosages of Escherichia coliderived recombinant human bone morphogenetic protein-2 using hydroxyapatite carrier. Spine J. 2012;12(3):239-48. https://doi.org/10.101 6/j.spinee.2012.01.013

14. Le H, Natesan K, Pranti-Haran S. Mechanical property and biocompatibility of co-precipitated nano hydroxyapatite-gelatine composites. J Adv Ceram 2015;4(3):237-43. https://doi.org/10.1007/s40145-015-0155-z.
15. Lee $\mathrm{KJH}$, Roper JG, Wang JC. Demineralized bone matrix and spinal arthrodesis. Spine J. 2005;5(6):S217-S23. https://doi.org/10.1016/j.spinee.2 005.02.006.

16. Huber E, Pobloth AM, Bormann N, Kolarczik N, Schmidt-Bleek K, Schell H, et al. $\left(^{*}\right)$ Demineralized bone matrix as a carrier for bone morphogenetic protein-2: burst release combined with long-term binding and osteoinductive activity evaluated in vitro and in vivo. Tissue Eng A. 2017; 23(23-24):1321-30. https://doi.org/10.1089/ten.tea.2017.0005.

17. Zhu W, Qiu Y, Sheng F, Yuan X, Xu L, Bao H, et al. An effective delivery vehicle of demineralized bone matrix incorporated with engineered collagen-binding human bone morphogenetic protein-2 to accelerate spinal fusion at low dose. J Mater Sci Mater Med. 2017;29(1):2. https://doi. org/10.1007/s10856-017-6007-3.

18. Tilkeridis K, Touzopoulos P, Ververidis A, Christodoulou S, Kazakos K, Drosos GI. Use of demineralized bone matrix in spinal fusion. World J Orthop. 2014; 5(1):30-7. https://doi.org/10.5312/wjo.v5.11.30.

19. Wildemann B, Kadow-Romacker A, Haas NP, Schmidmaier G. Quantification of various growth factors in different demineralized bone matrix preparations. J Biomed Mater Res A. 2007;81(2):437-42. https://doi.org/10.1 002/jbm.a.31085.

20. Jin YZ, Zheng GB, Lee JH. Escherichia coli BMP-2 showed comparable osteoinductivity with Chinese hamster ovary derived BMP-2 with demineralized bone matrix as carrier. Growth Factors (Chur, Switzerland) 2019:37(1-2):85-94.

21. Spicer PP, Kretlow JD, Young S, Jansen JA, Kasper FK, Mikos AG. Evaluation of bone regeneration using the rat critical size calvarial defect. Nat Protoc 2012;7(10):1918-29. https://doi.org/10.1038/nprot.2012.113.

22. Huh J-B, Lee H-J, Jang J-W, Kim M-J, Yun P-Y, Kim S-H, et al. Randomized clinical trial on the efficacy of Escherichia coli-derived rhBMP-2 with $\beta$-TCP/ HA in extraction socket. J Adv Prosthodont. 2011;3(3):161-5. https://doi. org/10.4047/jap.2011.3.3.161

23. Holt DJ, Grainger DW. Demineralized bone matrix as a vehicle for delivering endogenous and exogenous therapeutics in bone repair. Adv Drug Deliv Rev. 2012;64(12):1123-8. https://doi.org/10.1016/j.addr.2012.04.002

24. Tazaki J, Murata M, Akazawa T, Yamamoto M, Ito K, Arisue M, et al. BMP-2 release and dose-response studies in hydroxyapatite and beta-tricalcium phosphate. Biomed Mater Eng. 2009;19(2-3):141-6. https://doi.org/10.3233/ BME-2009-0573.

25. Lee JS, Lee SK, Kim BS, Im Gl, Cho KS, Kim CS. Controlled release of BMP-2 using a heparin-conjugated carrier system reduces in vivo adipose tissue formation. J Biomed Mater Res A. 2015;103(2):545-54. https://doi.org/10.1 002/jbm.a.35207.

26. Yang HS, La WG, Cho YM, Shin W, Yeo GD, Kim BS. Comparison between heparin-conjugated fibrin and collagen sponge as bone morphogenetic protein-2 carriers for bone regeneration. Exp Mol Med. 2012:44(5):350-5. https://doi.org/10.3858/emm.2012.44.5.039.

27. Gruskin E, Doll BA, Futrell FW, Schmitz JP, Hollinger JO. Demineralized bone matrix in bone repair: history and use. Adv Drug Deliv Rev. 2012;64(12): 1063-77. https://doi.org/10.1016/j.addr.2012.06.008

28. McGovern JA, Griffin M, Hutmacher DW. Animal models for bone tissue engineering and modelling disease. Dis Model Mech. 2018;11(4): dmm033084.

29. Lim J, Lee J, Yun H-S, Shin H-l, Park EK. Comparison of bone regeneration rate in flat and long bone defects: calvarial and tibial bone. Tissue Eng Regen Med. 2013;10(6):336-40. https://doi.org/10.1007/s13770-013-1094-9.

\section{Publisher's Note}

Springer Nature remains neutral with regard to jurisdictional claims in published maps and institutional affiliations. 